\title{
Características físicas e fisiológicas na qualidade industrial de cultivares e linhagens de trigo e triticale ${ }^{1}$
}

\author{
Adriana Smanhotto ${ }^{2}$, Lúcia H. P. Nóbrega ${ }^{3}$, Miguel A. U. Opazo ${ }^{3}$ \& Maritane Prior $^{2}$
}

\begin{abstract}
RESUMO
Estudaram-se as características físicas, fisiológicas e reológicas de cultivares e linhagens de trigo - cultivares CD (COODETEC) 103, 104, 105, 107, 108, 109, 110, 111, linhagens CD 2017 e CDFAPA 2036 e triticale (EMBRAPA 53), para qualidade de farinha destinada à panificação. Foram analisados: peso do hectolitro $(\mathrm{PH})$, peso de mil grãos (PMG), porcentagem de germinação, proteína total e farinografia, em delineamento experimental inteiramente casualizado, com quatro repetições, com exceção da farinografia, com duas repetições. As médias obtidas foram comparadas pelo teste de Scott Knott ao nível de 5\% de probabilidade. As cultivares diferiram entre si quanto aos parâmetros testados, atenderam ao valor de $\mathrm{PH}$ para comercialização mas nem sempre o maior PH correspondeu ao maior PMG; apenas as cultivares CD 108 e 111 poderiam ser destinadas à fabricação de pão francês quanto ao parâmetro estabilidade. Em relação ao índice de tolerância à mistura, as cultivares e linhagens não diferiram entre si, porém, a farinha da linhagem 2017 atenderia aos valores estabelecidos para fabricação de pão francês e biscoitos fermentados. As cultivares CD 104, 108, 111 e as linhagens CD 2017 e CDFAPA 2036 apresentaram índices ideais também para biscoitos fermentados. Cultivares que apresentaram menor PMG forneceram melhor índice de tolerância à mistura. Não houve correspondência entre a porcentagem de proteína total e a farinografia.
\end{abstract}

Palavras-chave: qualidade tecnológica, panificação, peso de mil grãos

\section{Physiological and physical characteristics in the industrial quality of cultivars and lines of wheat and triticale}

\begin{abstract}
The physical, physiological and rheological characteristics of cultivars and lines of wheat CD (COODETEC) 103, 104, 105, 107, 108, 109, 110, 111 and CD 2017 and CDFAPA 2036 lines and triticale (EMBRAPA 53), for quality of flour for bread making were studied. The weight of hectliter (HW), weight of thousand grains (WTG), percentage of germination, total protein and farinography, in a completely randomized experimental design, with four repetitions, except the farinography (with two repetitions) were analyzed. The means obtained were compared by the Scott Knott test at $5 \%$. The cultivars were different regarding the tested parameters. The $\mathrm{PH}$ value were compatible for commercialization, but not always the higher $\mathrm{PH}$ value corresponded to the greater weight of thousand grains. Only the CD 108 and 111 cultivars may be destine for French bread considering the stability parameter. About the index of tolerance for the mixture, the cultivars and lines were not different, but only the flour of 2017 line would attend the values that were established for French bread-making and fermented cookies. The CD 104, 108 and 11 cultivars and the CD 2017 and CDFAPA 2036 line obtained the ideal index also for fermented cookies. The cultivars which presented better weight of thousand grain gave the best index of tolerance for the mixture. There was no positive relation between total protein and the farinography.
\end{abstract}

Key words: technological quality, panification, weight of thousand grains

\footnotetext{
${ }^{1}$ Parte da dissertação de mestrado da primeira autora apresentada ao Programa Pós-Graduação em Engenharia Agrícola da Universidade Estadual do Oeste do Paraná - CCET/UNIOESTE.

${ }^{2}$ FCA/UNESP, Fazenda Lageado, Rua José Barbosa de Barros, nº 1780, Rodovia Alcides Soares, Km 3, CEP 18610-307, Botucatu, SP. Fone: (14) 3811-7100. E-mail: adrisman@fca.unesp.br; maritane@fca.unesp.br

${ }^{3}$ CCET/UNIOESTE, Campus de Cascavel, Rua Universitária, 2069, Bairro Jardim Universitário, CEP 85819-110, Cascavel, PR. Fone: (45) 3220-3000. E-mail: Ihpn@unioeste.br; mopazo@unioeste.br
} 


\section{INTRODUÇÃO}

A característica produtividade, ligada à qualidade industrial em diferentes regiões, é uma das exigências não só das indústrias moageiras e panificadoras, mas também, dos produtores de grãos de trigo. O melhoramento da qualidade representa uma oportunidade de se agregar valor de mercado aos produtos agrícolas. No caso do trigo e em face do comércio internacional, existe forte interação entre a qualidade e o preço.

A qualidade de grãos e farinhas de cereais é determinada por uma variedade de características que assumem diferentes significados, dependendo da designação de uso ou do tipo de produto. Essas características podem ser divididas em físicas, químicas, enzimáticas e reológicas (Rasper, 1991).

A qualidade de uma cultivar ou linhagem é resultado de uma série de fatores, como característica genética, condições edafoclimáticas, técnicas de cultivo, colheita, secagem e armazenamento, moagem e, por fim, no uso industrial a ser dado à farinha. Referidos resultados influem na expressão da qualidade industrial da cultivar em estudo (Gutdoski \& Silveira, 1999).

Embora alguns genes relacionados à produtividade possam influenciar diretamente nos componentes de rendimento, muitos atuam indiretamente, por meio de processos fisiológicos, interferindo na expressão de outros caracteres das plantas; portanto, se os fatores externos que prejudicam o desenvolvimento da planta de trigo não forem controlados de maneira correta, isto implicará na redução da produção de grãos, visto que a disponibilidade de carboidratos para o suprimento da demanda requerida para aumento do peso de grãos, foi reduzida (Frankel et al., 1981).

A fabricação de pães em escala comercial é uma das maiores utilizações da farinha de trigo; portanto, as cultivares desenvolvidas devem ter o potencial de produzir uma farinha que confira, ao produto final, as características de crescimento, textura, sabor e coloração desejada e, ainda, apresente adequação ao processo mecânico de preparo (Mittelmann et al., 2000).

No Brasil, o controle de qualidade das farinhas em relação às características tecnológicas, é deficiente. A comercialização é feita sem a discriminação do tipo e sem finalidade específica, razão por que há necessidade de adequação das farinhas disponíveis, para otimização dos processos de produção (Gutkoski \& Silveira, 1999).

Conhecendo-se a carência do produtor em obter safras de alta produtividade em diferentes áreas e a preocupação da indústria em incrementar a qualidade dos trigos para fins de panificação objetivou-se, com este trabalho, avaliar a qualidade industrial quanto a: proteínas e farinografia, características físicas (peso do hectolitro, peso de mil grãos) e fisiológicas (teste de germinação) de cultivares e linhagens de trigo e uma cultivar de triticale, recomendadas para a região Oeste do Paraná.

\section{MATERIAL E MÉTODOS}

As sementes das cultivares estudadas foram produzidas pela Cooperativa Central de Pesquisa Agrícola - COODETEC, localizada na PR 364, km 98, Palotina,PR. O solo do local é classificado como Latossolo Vermelho Eutroférrico, sem a presença de alumínio tóxico, latitude $24^{\circ} 18^{\prime} \mathrm{S}$, longitude $53^{\circ}$ $55^{\prime} \mathrm{W}$ e altitude de $360 \mathrm{~m}$. O clima é subtropical, com verão quente, temperatura média anual superior a $21^{\circ} \mathrm{C}$ e pluviosidade média anual de $1400 \mathrm{~mm}$, com umidade relativa do ar média de $85 \%$. Foram utilizadas oito cultivares de trigo: $\mathrm{CD}$ 103, CD 104, CD 105, CD 107, CD 108, CD 109, CD 110 e CD 111, além de duas linhagens: CD 2017 e CDFAPA 2036 e uma cultivar de triticale, Embrapa 53, do ano agrícola 2001/2002, sendo as mesmas sementes básicas de ciclo precoce e médio, com características distintas quanto à reação ao acamamento, porte de planta e susceptibilidade a determinadas doenças e germinação na espiga. A escolha das cultivares foi predefinida em conjunto com a COODETEC, recomendadas para a região Oeste do Paraná.

A determinação do PH para cada cultivar foi realizada em medidor de peso do hectolitro, tendo por princípio a pesagem de volume conhecido de sementes. $\mathrm{O}$ PH foi obtido pela massa de sementes contidas em $125 \mathrm{~mL}$, por cultivar; transformado para massa de sementes, que ocupa o volume de 100 L (Brasil, 1992).

Para determinação do peso de mil grãos foram contadas, ao acaso e manualmente, quatro amostras de 100 sementes puras, para cada cultivar; em seguida, essas amostras foram pesadas em balança de precisão $0,001 \mathrm{~g}$ e os valores médios, expressos em g, transformados para 1000 sementes (Brasil,1992).

A avaliação da qualidade fisiológica das sementes foi realizada por meio de quatro repetições de 50 sementes de cada cultivar, semeadas em folhas de papel filtro, tipo Germitest, umedecidas em água destilada, enroladas e colocadas no germinador a temperatura de $25^{\circ} \mathrm{C}$, pelo período de oito dias. A contagem do número de plântulas normais, expressa em porcentagem, seguiu as recomendações estabelecidas por Brasil (1992).

Quanto ao parâmetro qualidade industrial do trigo, realizou-se o teste reológico através da farinografia, com base no método 54-21 da American Association of Cereal Chemists AACC (1999), em amostras duplicadas para cada cultivar. Pesaram-se $100 \mathrm{~g}$ de farinha corrigidos para $14 \%$ de umidade e levados ao farinógrafo da marca Max Egger, no qual se adicionou água destilada até que a massa adquirisse consistência padrão (atingisse a linha das 500 unidades farinográficas). Todas as fases de mistura, de desenvolvimento e de quebra foram registradas em gráfico farinograma. Os resultados foram expressos em minutos.

O teor de proteína total foi determinado conforme Instituto Adolfo Lutz (1985), retirando-se quatro repetições de $2 \mathrm{~g}$ de cada cultivar, realizando-se a digestão pelo processo de Kjedahl e, em seguida, destilando para liberação de amônia e se determinando os processos de destilação e titulação. Os valores foram expressos em porcentagem para determinação da proteína total.

O delineamento experimental foi inteiramente casualizado, com nove cultivares e duas linhagens (11 tratamentos) com quatro repetições para cada uma. As amostras de cada cultivar foram obtidas aleatoriamente da composição de subamos- 
tras recolhidas de quatro parcelas no campo. A análise estatística dos dados foi realizada pela transformação arcsen $\sqrt{x / 100}$, para os dados expressos em porcentagem, e $\sqrt{x}$ para os dados de contagens que não apresentaram normalidade, conforme Banzato \& Kronka (1992). A comparação das médias se deu pelo teste de Scott-Knott (Scott \& Knott, 1974; Cruz, 2001) a nível de 5\% de significância.

\section{RESULTADOS E DISCUSSÃO}

Na Tabela 1 é apresentada a comparação dos valores médios para peso do hectolitro e o peso de mil grãos das cultivares e linhagens de trigo e triticale, observando-se que as cultivares e linhagens diferiram entre si quanto ao peso do hectolitro. A linhagem CDFAPA 2036 apresentou maior média, enquanto as cultivares CD 109 e CD 111 indicaram as menores mas sem diferenças significativas entre si, diferindo das demais cultivares e linhagens; nota-se que as cultivares e linhagens atenderam à exigência de $\mathrm{PH}$ maior que $70 \mathrm{~kg} \mathrm{hL}^{-1}$, conforme a Instrução Normativa $n^{\circ} 7$ (Brasil, 2001).

Os valores médios de peso de mil grãos também diferiram entre si. A cultivar CD 103 apresentou maior média, não diferindo, portanto, da BR 53 mas, sim, das demais. Nota-se que a cultivar CD 111 obteve menor peso divergindo das demais cultivares e linhagens. As cultivares CD 104 e CD 110 foram semelhantes entre si, porém diferiram das demais; o mesmo comportamento pode ser observado entre a cultivar CD 109 e as linhagens CD 2017 e CDFAPA 2036, enquanto as demais cultivares foram semelhantes entre si. Guarienti (1996) relatou que o peso de mil grãos é uma medida que apresenta forte controle genético mas também é afetado por condições edafoclimáticas durante a fase de maturação.

Neste trabalho, as cultivares e linhagens foram semeadas na mesma época, porém, com maturação em épocas distintas, conforme IAPAR (2003), o que explicaria tal diferença no peso de mil sementes, concordando com Guarienti (1996), uma vez que pode ter ocorrido condições adversas de clima, provocando maior ou menor peso, de acordo com as médias obtidas para cada cultivar (IAPAR, 2003).

Segundo Williams et al., apud Guarienti (1996), pode-se classificar o trigo quanto ao peso de mil grãos, ou seja, as cultivares CD 104, CD 109, CD 110 e CD 111 e as linhagens
CD 2017 e CDFAPA 2036, seriam classificadas como grãos pequenos $(26-35 \mathrm{~g})$, e as demais cultivares o seriam como grãos médios (36-45 g ). Para os autores, grãos de tamanho excessivo não são desejados pela indústria pois podem provocar problemas nos equipamentos de limpeza e de moagem; por outro lado, os autores citaram que grãos muito pequenos também não são almejados, pois podem passar pelas peneiras de limpeza e acarretar perda na produção de farinhas, devido à diminuição de trigo moído.

Posner (1990) observou relação positiva entre o tamanho do grão e a quantidade de sêmola produzida; desta forma, as cultivares CD 103 e BR 53 produziriam maior quantidade de sêmola.

Comparando-se os dois parâmetros, peso do hectolitro e peso de mil grãos, verifica-se que não há relação entre eles, ou seja, nem sempre o maior peso do hectolitro correspondeu ao maior peso de mil grãos, fato também observado em estudos realizados por Prior (2003) e Sordi (2003). Cada cultivar possui tamanho distinto do grão e, conseqüentemente, peso diferente. O PH é a massa dividida por um volume conhecido; independente do tamanho do grão, o volume será constante, enquanto o peso de mil grãos não envolve volume, mas apenas massa, podendo explicar a falta de correspondência.

Na Tabela 2 são apresentadas, as porcentagens médias de plântulas normais obtidas no teste de germinação das sementes de cultivares e linhagens de trigo e triticale. As cultivares diferiram entre si. A maior porcentagem média de germinação ocorreu na cultivar CD 104, a qual não diferiu das CD 103, CD 105, CD 107, CD 110 nem da CD 111, BR 53 e a linhagem CDFAPA 2036, diferindo da CD 109 e da linhagem CD 2017, as quais diferiram entre si e de todas as demais. A cultivar CD 109 apresentou a menor porcentagem média de germinação.

Segundo CLASPAR (1986) as porcentagens mínimas de germinação para sementes básicas de trigo não podem ser inferiores a $60 \%$; desta forma, as sementes analisadas são viabilizadas para comercialização pela alta porcentagem de germinação apresentada.

Tem-se, na Tabela 3, os valores médios de proteína total dos grãos das cultivares e linhagens de trigo e triticale, observando-se que a maior média foi apresentada pela cultivar CD 109, a qual diferiu estatisticamente das demais. As culti-

Tabela 1. Médias* de peso do hectolitro (PH), peso de mil grãos (PMG) (g) das cultivares e linhagens de trigo e triticale

\begin{tabular}{|c|c|c|c|c|c|c|c|c|c|c|c|}
\hline & \multicolumn{9}{|c|}{ Cultivares } & \multicolumn{2}{|c|}{ Linhagens } \\
\hline & CD 103 & CD 104 & CD 105 & CD 107 & CD 108 & CD 109 & CD 110 & CD 111 & BR 53 & CD 2017 & CD FAPA 2036 \\
\hline PH & $74 \mathrm{~B}$ & $73 \mathrm{~B}$ & $74 \mathrm{~B}$ & $75 \mathrm{~B}$ & $79 \mathrm{D}$ & $71 \mathrm{~A}$ & $77 \mathrm{C}$ & $71 \mathrm{~A}$ & $74 \mathrm{~B}$ & $75 \mathrm{~B}$ & $80 \mathrm{D}$ \\
\hline PMG & $40,9 \mathrm{E}$ & $31,5 \mathrm{~B}$ & $37,3 \mathrm{D}$ & $36,0 \mathrm{D}$ & $36,7 \mathrm{D}$ & $34,1 \mathrm{C}$ & 30,3 B & $28,2 \mathrm{~A}$ & $40,6 \mathrm{E}$ & $34,5 \mathrm{C}$ & $34,0 \mathrm{C}$ \\
\hline
\end{tabular}

*Médias seguidas de mesma letra na linha não diferem entre si pelo teste de Scott - Knott ao nível de 5 \% de significância.

Tabela 2. Porcentagem média* de plântulas normais obtidas pelo teste de germinação das sementes de cultivares e linhagens de trigo e triticale

\begin{tabular}{|c|c|c|c|c|c|c|c|c|c|c|c|}
\hline & \multicolumn{9}{|c|}{ Cultivares } & \multicolumn{2}{|c|}{ Linhagens } \\
\hline & CD 103 & CD 104 & CD 105 & CD 107 & CD 108 & CD 109 & CD 110 & CD 111 & BR 53 & CD 2017 & CD FAPA 2036 \\
\hline Plântulas Normais (\%) & $84 \mathrm{C}$ & $94 \mathrm{C}$ & $88 \mathrm{C}$ & $93 \mathrm{C}$ & $90 \mathrm{C}$ & $70 \mathrm{~A}$ & $91 \mathrm{C}$ & $90 \mathrm{C}$ & $90 \mathrm{C}$ & $81 \mathrm{~B}$ & $91 \mathrm{C}$ \\
\hline
\end{tabular}


Tabela 3. Porcentagem média* de proteína dos grãos das cultivares e linhagens de trigo e triticale

\begin{tabular}{|c|c|c|c|c|c|c|c|c|c|c|c|}
\hline & \multicolumn{9}{|c|}{ Cultivares } & \multicolumn{2}{|c|}{ Linhagens } \\
\hline & CD 103 & CD 104 & CD 105 & CD 107 & CD 108 & CD 109 & CD 110 & CD 111 & BR 53 & CD 2017 & CD FAPA 2036 \\
\hline Proteínas (\%) & $11,53 \mathrm{C}$ & $12,76 \mathrm{D}$ & $12,14 \mathrm{C}$ & $11,07 \mathrm{~B}$ & $12,81 \mathrm{D}$ & $16,38 \mathrm{E}$ & $9,87 \mathrm{~A}$ & $9,87 \mathrm{~A}$ & $11,81 \mathrm{C}$ & $12,63 \mathrm{D}$ & $11,62 \mathrm{C}$ \\
\hline
\end{tabular}

${ }^{*}$ Médias seguidas da mesma letra na linha, não diferem entre si pelo teste de Scott-Knott a nível de 5\% de significância. 0s dados apresentados são os obtidos das observações originais seguidos das letras obtidas na comparação de médias com a transformação em $\sqrt{x}$

Tabela 4. Valores médios* de absorção de água (\%), tempo de desenvolvimento da massa (TDM), estabilidade, índice de tolerância a mistura (ITM) das cultivares e linhagens de trigo e triticale

\begin{tabular}{|c|c|c|c|c|c|c|c|c|c|c|c|}
\hline & \multicolumn{9}{|c|}{ Cultivares } & \multicolumn{2}{|c|}{ Linhagens } \\
\hline & CD 103 & CD 104 & CD 105 & CD 107 & CD 108 & CD 109 & CD 110 & CD 111 & BR 53 & CD 2017 & CD FAPA 2036 \\
\hline Absorção (\%) ${ }^{1}$ & $53,3 \mathrm{~B}$ & $55,5 \mathrm{C}$ & $53,8 \mathrm{~B}$ & 53,3 B & $58,8 \mathrm{G}$ & $57,3 \mathrm{~F}$ & $56,8 \mathrm{E}$ & $55,3 \mathrm{C}$ & $48,0 \mathrm{~A}$ & $56,0 \mathrm{D}$ & $56,0 \mathrm{D}$ \\
\hline TDM (min) & 3,3 B & $5,3 \mathrm{D}$ & 4,7 C & 3,3 B & $8,2 \mathrm{~F}$ & $5,2 \mathrm{D}$ & $6,5 \mathrm{E}$ & 4,7 C & $0,3 \mathrm{~A}$ & $5,0 \mathrm{C}$ & $5,7 \mathrm{D}$ \\
\hline Estabilidade (min) & $4,3 \mathrm{~A}$ & $9,5 \mathrm{C}$ & $5,3 \mathrm{~A}$ & $7,2 \mathrm{~B}$ & $14,8 \mathrm{E}$ & $6,3 B$ & $7,3 \mathrm{~B}$ & $15,3 \mathrm{E}$ & $4,2 \mathrm{~A}$ & $3,7 \mathrm{~A}$ & $11,2 \mathrm{D}$ \\
\hline ITM $^{2}\left(\right.$ U.F. $\left.{ }^{3}\right)$ & $90 \mathrm{D}$ & $60 \mathrm{~B}$ & $70 \mathrm{C}$ & $130 \mathrm{E}$ & $55 \mathrm{~B}$ & $80 \mathrm{C}$ & $80 \mathrm{C}$ & $60 \mathrm{~B}$ & $100 \mathrm{D}$ & $40 \mathrm{~A}$ & $60 \mathrm{~B}$ \\
\hline
\end{tabular}

* Médias seguidas da mesma letra maiúscula na linha, não diferem entre si pelo teste de Scott-Knott a nível de $5 \%$ de significância.

1 os dados apresentados são os obtidos das observações originais seguidos das letras obtidas na comparação de médias com a transformação em arcsen $\sqrt{x / 100}$

2 Índice de tolerância à mistura: diferença em unidades farinográficas (U.F.) do topo da curva no pico e o topo da curva medindo 5 min após 0 pico ser alcançado

3 U.F.: unidades farinográficas.

vares CD 103, CD 105, BR 53 e a linhagem CDFAPA 2036, não diferiram entre si mas, sim, das demais. A menor porcentagem de proteína foi apresentada pelas cultivares CD 110 e CD 111, semelhantes entre si e diferentes das demais.

Conforme Rosa Filho \& Rosa (1999) as características reológicas únicas do trigo se derivam principalmente do componente protéico, podendo este variar tanto em qualidade (cultivar) como em quantidade (porcentagem de proteína). Os mercados exportadores mais avançados usam não apenas a genética como, também, a porcentagem de proteína no grão para classificar e cotar trigos, sendo que trigos de alto teor protéico (15\%) são, em geral, mais valorizados comercialmente; assim apenas a cultivar CD 109 se enquadraria nesses padrões.

Para a fabricação de pão francês, o teor de proteína ideal do grão se situa na faixa de 10,5 a 13,0\%; para pão de forma (tipo sanduíche), de 11,5 a 14,5\%; para bolachas tipo cracker, de 8,5 a 10,5\%; para os demais tipos de bolacha, de 7,5 a 9,0\%; para bolos, de 5 a 7,5\% e para massas curtas, de 8,5 a $10,5 \%$ (Schiller apud Guarienti, 1996). Desta forma, as cultivares CD 110 e CD 111 serviriam para fabricação de bolachas tipo cracker e a cultivar CD 109 poderia ser utilizada para pão de forma, embora esteja acima da faixa; as demais poderiam ser utilizadas na fabricação de pão francês. No que se refere ao teor de proteína ideal, este parâmetro é apenas um complemento dos demais a serem analisados, pois a qualidade de panificação do trigo depende da quantidade e da qualidade das proteínas presentes no grão (Felício et al., 2001).

$\mathrm{Na}$ Tabela 4 são apresentados os valores médios da absorção de água, tempo de desenvolvimento da massa (TDM), estabilidade e índice de tolerância à mistura (ITM).

Verificam-se diferenças quanto à absorção de água. A cultivar CD 108 apresentou maior porcentagem média, diferindo das demais cultivares. Por outro lado, a cultivar BR 53 apresentou a menor média e diferiu das demais. As cultivares CD 103, CD 105 e CD 107 não apresentaram diferenças entre si mas divergiram das demais. As linhagens CD 2017 e CDFAPA 2036 não diferiram entre si, obtendo a mesma proporção média e diferindo das cultivares.
Observando os valores médios de absorção de água, notase que apenas a farinha obtida da cultivar CD 108 atenderia aos valores estabelecidos para a fabricação de massas, pão francês, bolos, biscoitos fermentados, biscoitos amanteigados, uma vez que, o mínimo, para todos esses produtos é de 58\%; de acordo com estudos realizados no Moinho Agrícola Horizonte Ltda. (2003). Nota-se ainda que a faixa de absorção de água ficou entre 53 a 58\%, exceto para a cultivar BR 53, que apresentou menos que $50 \%$ de absorção, discordando de Felício et al. (1989) que compararam as características farinográficas do trigo e triticale e encontraram valores de absorção de água das farinhas de triticale entre 55 e $65 \%$, enquanto as farinhas provenientes das culivares de trigo indicaram valores superiores a $60 \%$.

Observa-se, ainda na Tabela 4, que as cultivares e linhagens diferiram significativamente entre si quanto ao tempo de desenvolvimento da massa. As cultivares CD 105 e 111 mostraram as maiores porcentagens medias e foram semelhantes entre si, diferindo das demais cultivares, por outro lado, a cultivar BR 53 apresentou a menor média e diferiu das demais. As cultivares CD 103 e CD 107 não diferiram entre si, mas, sim das demais. Praticamente, todas as farinhas obtidas das cultivares atenderiam aos valores estabelecidos para a fabricação de massas, pão francês e biscoitos fermentados, uma vez que a faixa de desenvolvimento para esses produtos é de três a oito minutos, de acordo com estudos realizados no Moinho Agrícola Horizonte Ltda (2003); no entanto, para fabricação de bolos e biscoitos amanteigados, as cultivares CD 108 e CD 110 e a linhagem CDFAPA 2036 mostraram valores maiores que os da faixa ideal para a fabricação desses produtos, a qual é de dois a 5 min. A cultivar BR 53 indicou tempo de desenvolvimento bem abaixo do recomendável, para qualquer produto final, sendo novamente recomendada para outros usos, como em rações e colas, ou até mesmo na utilização de mesclas com farinhas obtidas de cultivares de trigo. 
Comparando-se os dados de absorção de água e o tempo de desenvolvimento com os de peso de mil grãos (Tabela 1), nota-se que não há associação entre os parâmetros, ou seja, nem sempre os grãos maiores obtiveram maior tempo de desenvolvimento, obtendo resultados diferentes de Posner (1990) o qual constatou que a farinha resultante de grãos maiores apresenta também maior absorção de água e tempo de desenvolvimento (pela farinografia) que a farinha resultante de grãos pequenos.

Pelos valores médios de estabilidade nota-se que a maior média foi verificada na cultivar CD 111, a qual foi semelhante à $\mathrm{CD} 108$, diferindo das demais, que apresentaram menores médias. As cultivares BR 53, CD 103, CD 105 e a linhagem CD 2017 foram semelhantes entre si quanto ao parâmetro avaliado mas diferiram das demais. Observa-se também o mesmo comportamento nas cultivares CD 107, CD 109 e CD 110 e as cultivares CD 104 e linhagem CDFAPA 2036 diferiram entre si e das demais. Verifica-se, pela Tabela 4, que apenas as cultivares CD 108 e 111 poderiam ser destinadas à fabricação de pão francês, segundo o parâmetro estabilidade, uma vez que a faixa ideal é de 12-15 min, de acordo com estudos realizados no Moinho Agrícola Horizonte Ltda (2003).

Quanto ao índice de tolerância à mistura, observa-se que as cultivares e linhagens diferiram entre si. As cultivares CD 104, 108, 111 e a linhagem CDFAPA 2036 foram semelhantes entre si e diferiram das demais. $\mathrm{O}$ mesmo comportamento pode ser constatado nas cultivares CD 103 e BR 53 e nas cultivares $C D$ 105, 109 e 110. Pelos valores médios apresentados nota-se que apenas a farinha obtida da linhagem 2017 atenderia aos valores estabelecidos para a fabricação de pão francês e biscoitos fermentados, uma vez que a faixa ideal é de 20-40 U.F e 40-60 U.F, respectivamente. As cultivares CD 104, CD 108, CD 111 e as linhagens CD 2017 e CDFAPA 2036 também apresentaram índices ideais para biscoitos fermentados, conforme estudos realizados no Moinho Agrícola Horizonte Ltda (2003). Comparando-se a Tabela 4 (ITM) com a Tabela 2 (PMG), vê-se que as cultivares que apresentaram menores PMG indicaram melhores ITM, obtendo resultados semelhantes com Posner (1990), o qual afirmou que as farinhas resultantes de grãos pequenos mostraram melhor tolerância à mistura; nota-se ainda que a cultivar CD 108, num contexto geral do teste de farinografia teve melhor desempenho quando comparada às demais cultivares e linhagens.

\section{CONCLUSÕES}

1. Apenas as cultivares CD 108 e 111 poderiam ser destinadas à fabricação de pão francês quanto ao parâmetro estabilidade.

2. Em relação ao índice de tolerância à mistura, apenas a farinha obtida da linhagem 2017 atenderia aos valores estabelecidos para a fabricação de pão francês e biscoitos fermentados.

3. As cultivares CD 104, 108 e 111 e as linhagens CD 2017 e CDFAPA 2036 também apresentaram índices ideais para biscoitos fermentados.

4. Não houve correspondência entre a porcentagem de proteína total e a farinografia.

\section{LITERATURA CITADA}

AACC - American Association of Cereal Chemists. Aproved methods. 10 ed, Saint Paul: AACC, 1999.

Banzatto, D.A.; Kronka, S. do N. Experimentação agrícola. Jaboticabal: FUNEP, 1992, 247p.

Brasil. Regras para análise de sementes. Ministério da Agricultura e reforma agrária. Brasília: 1992. 365p.

Brasil. Ministério da Agricultura, do Abastecimento e da Reforma Agrária. Instrução normativa n.7, de 15 de agosto de 2001. Define as características de identidade e qualidade do trigo. Diário Oficial da República Federativa do Brasil, Brasília, 15 Ago. 2001. s.p.

CLASPAR - Empresa Pranaense de Classificação de Produtos. Normas de produção de sementes. Curitiba: CLASPAR, 1986, 130p.

Cruz, C.D. Aplicativo computacional em genética e estatística. Programa Genes, Versão Windows. UFV, MG. 2001, 648p.

Felício, J.C.; Camargo, C.E. de O.; Camargo, C.R. de O. Competição e avaliação tecnológica de cultivares de triticale na região norte do estado de São Paulo. Pesquisa Agropecuária Brasileira, Brasília, v.24, n, 7, p.819-828, 1989.

Felício, J.C.; Camargo, C.E.de O.; Germani, R.; Gallo, P.B.; Pereira, J.C.V.N.A.; Bortoletto, N.; Pettinelli, A.J. Influência do ambiente no rendimento e na qualidade de grãos de genótipos de trigo com irrigação por aspersão no estado de São Paulo. Bragantia, Campinas, v.60, n, 2, p.111-120, 2001.

Frankel, O.H.; Knox, R.B.; Considine, J.A.. The development of the wheat flower: genetics and physiology. In: Evans, L.T.; Peacock, W.J.Wheat Science, Cambridge: Cambridge University Press, p. 167-189, 1981.

Guarienti, E.M. Qualidade industrial de trigo. Passo Fundo: Embrapa-CNPT, 1996. 36p. Documentos, 27.

Gutdoski, L.C.; Silveira, L. Avaliação reológica de cultivares de trigo para a produção de biscoitos. In: Reunião Nacional de Pesquisa de Trigo, 18., 1999, Passo Fundo. Anais... Passo Fundo: Embrapa Trigo. v.2, p.386-390, 1999.

IAPAR - Instituto Agronômico do Paraná. Informações técnicas para a cultura do trigo e triticale no Paraná 2003. Londrina, 202 p. 2003. Circular Técnica, 126.

Instituto Adolfo Lutz. Normas analíticas do Instituto Adolfo Lutz: Métodos químicos para análise de alimentos. São Paulo: 3 ed. 1985, 533p.

Mittelmann, A.; Neto Barbosa, J.F.; Carvalho, F.I.F. de; Lemos, M.C.I.; Conceição, L.D. da. Herança de caracteres do trigo relacionados à qualidade de panificação. Pesquisa Agropecuária Brasileira: Brasília. v.35, n.5, p.975-983, 2000.

Moinho Agrícola Horizonte Ltda. Especificações de farinha de trigo. Marechal Cândido Rondon, 2003, s.p.

Posner, E.S. La influencia del tamano del grano de trigo sobre la aptitud molinera. In: Seminário Técnico-Econômico de Molineria, 1990, Fortaleza, Anais... p.20-31, 1990.

Prior, M. Resposta de cultivares de trigo (triticum aestivum) a épocas de semeadura. Cascavel: UNIOESTE, 2003. 63p. Dissertação Mestrado

R. Bras. Eng. Agríc. Ambiental, v.10, n.4, p.867-872, 2006. 
Rasper, V.F. Quality evaluation of cereal and cereal products. In: Lorenz, K.J; Kulp, K. ed. Handbook of cereal science and technology. New York: Marcel Dekker, p. 595-638, 1991.

Rosa Filho, O.; Rosa, O.S. Avaliação reológica de cultivares de trigo para a produção de biscoitos. In: Reunião Nacional de Pesquisa de Trigo, 18., 1999, Passo Fundo. Anais... Passo Fundo: Embrapa Trigo. v.2, p.386-390, 1999.
Scott, A.J.; Knott, M.A.A cluster analysis method for grouping means in the analysis of variance. Biometrics, North Carolina, v.30, n.3, p.507-512, 1974.

Sordi, C. Resposta de cultivares de trigo (triticum aestivum) a teores de alumínio no solo. Cascavel: UNIOESTE, 2003. 70p. Dissertação Mestrado 